\title{
Analysis of trends in the development of hybrid housing: European experience of the 21st century
}

\author{
Olha Khymytsia \\ Department of Architectural Constructions, Lviv Politechnic National University, Ukraine, Lviv, St. Bandery Street, 12, E-mail: \\ olha.khymytsya@gmail.com.
}

\begin{abstract}
The European experience of designing and constructing hybrid housing in the beginning of the XXI century is analyzed, the main tendencies and features are determined.
\end{abstract}

Keywords - Hybrid housing, design, planning, european experience, XXI century.

\section{Introduction}

Mixed-use buildings are organizations with several interconnected programs designed to accommodate both planned activities and unplanned urban activities. In the 21 st century, the demand for building hybrids is increasing, as the processes of hyper-urbanization act as a catalyst for new experimental architectural typologies. Hybrids are characterized by mixing functions in one project. This is a "full time" building with a 24-hour working day, as they combine private and public life together. Typically, these buildings are unusual, unique, often shaping the image of the entire city space, building landmarks. Hybrid houses are actively interacting with the environment, often with an environment with historical value. The need for the development of hybrid complexes in Ukraine makes it particularly relevant to systematize the advanced European experience to identify on its basis the principles of the formation of hybrid complexes and to develop recommendations for their placement in the city structure.

\section{Analysis of researches and publications}

The concept of hybridization comes from genetics and associated with cross-breeding of different species. In spite of the fact that in the past functions were combined into a single structure, for example, a house-store or a residential bridge (Ponte Vecchio in Florence), hybrid buildings appeared in full scale only in the XIX century.

In the first study of hybrids, the American architect Joseph Fenton identified three main types of hybrid buildings: Contextual hybrid - the shape of the complex determined by external constraints, so that the complex program fits completely into the given shell, and relatively weakly manifested outside. Combined hybrid - each function has its own form, and the whole formed as a complex combination of individual elements. Monolithic hybrid - a self-contained monumental form of allcity scale, which contains all the components of the functional program [1, p.8]. In the article "Hybrid Power and Art of Mixing," Martin Mussuovitz classifies hybrid buildings on: "monolithic hybrids", "cities in cities", "combined structures", "overlapping and spatial uncertainty", "integrated landscapes" [2, p.13]. Plotteg emphasizes the features of modern hybrid structures, emphasizes the special role of complex computer technologies in the process of hybridization of buildings [3]. The theme of hybrid buildings is thoroughly explored in the collection" This is HYBRID An analysis of mixed-use buildings. "A prologue written by Stephen Hall specifically for this compilation puts forward the potential of hybrid buildings in the 21 st century [4]. The purpose of the study is to analyze the modern European experience in the design and construction of hybrid housing, to identify the main trends in this area of architecture. 


\section{Analysis of foreign experience in the design and planning of hybrid housing} Le Monolithe (Location: Lyon, France)
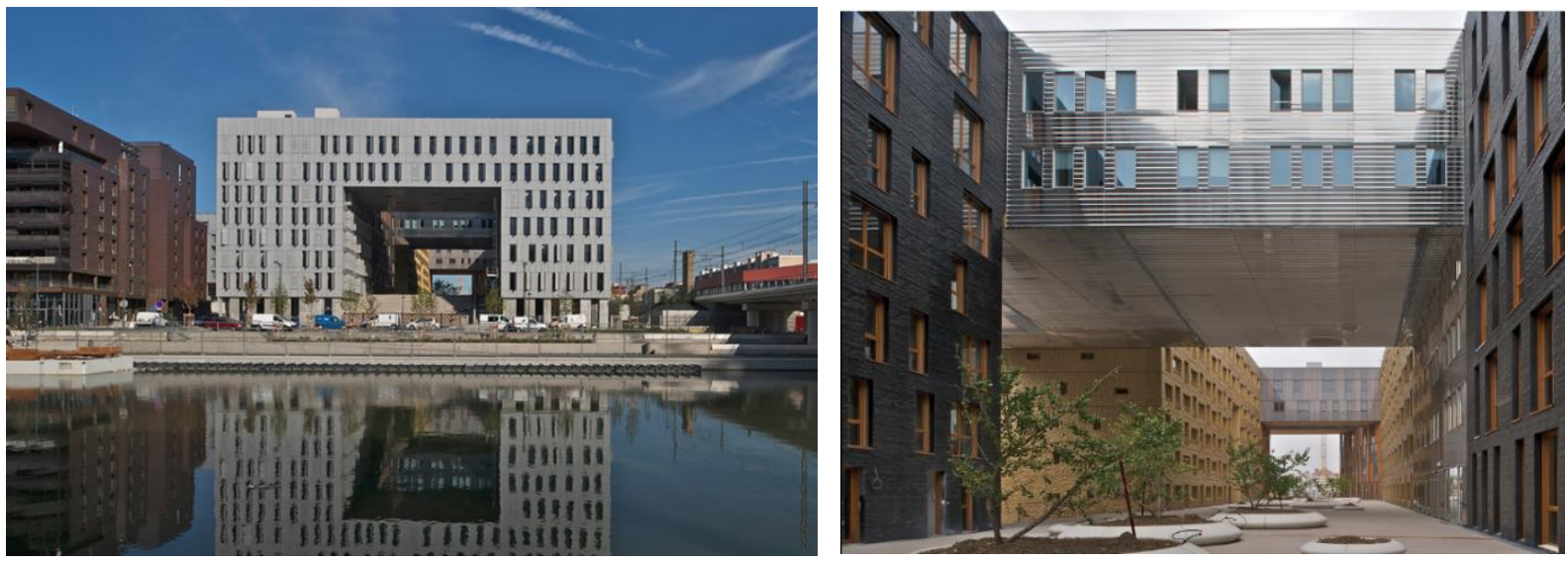

Fig 1. Le Monolithe.

It is a city functional building hybrid, consisting of social and rental housing, offices and underground parking. The building boasts a large courtyard with a raised public space overlooking the city, the new marina and the park. The interiors of the building protected from the sun by means of a system of aluminum louvres.

The building blocks divided into five sections, each of which designed by another architect in order to achieve diversity and architectural creativity. Le Monolithe has a very wide range of apartments planning to accommodate different categories of residents and reflect the diversity of the population of Lyon. Offices divided into separate units of at least $500 \mathrm{~m}^{2}$.

The building meets high environmental requirements (HQE), such as solid insulation, careful selection of materials in accordance with the sustainability requirements, and rainwater management. $80 \%$ of the total energy consumption is provided by renewable energy sources. The building combines an effective spatial composition, passive energy, thermal and acoustic comfort, and an energy strategy that includes a heat storage, low-emission double glazing, compactness to minimize heat loss, natural ventilation and eco-friendly energy.

\section{Residential Complex Hypérion (Location: France, Bordeaux)}

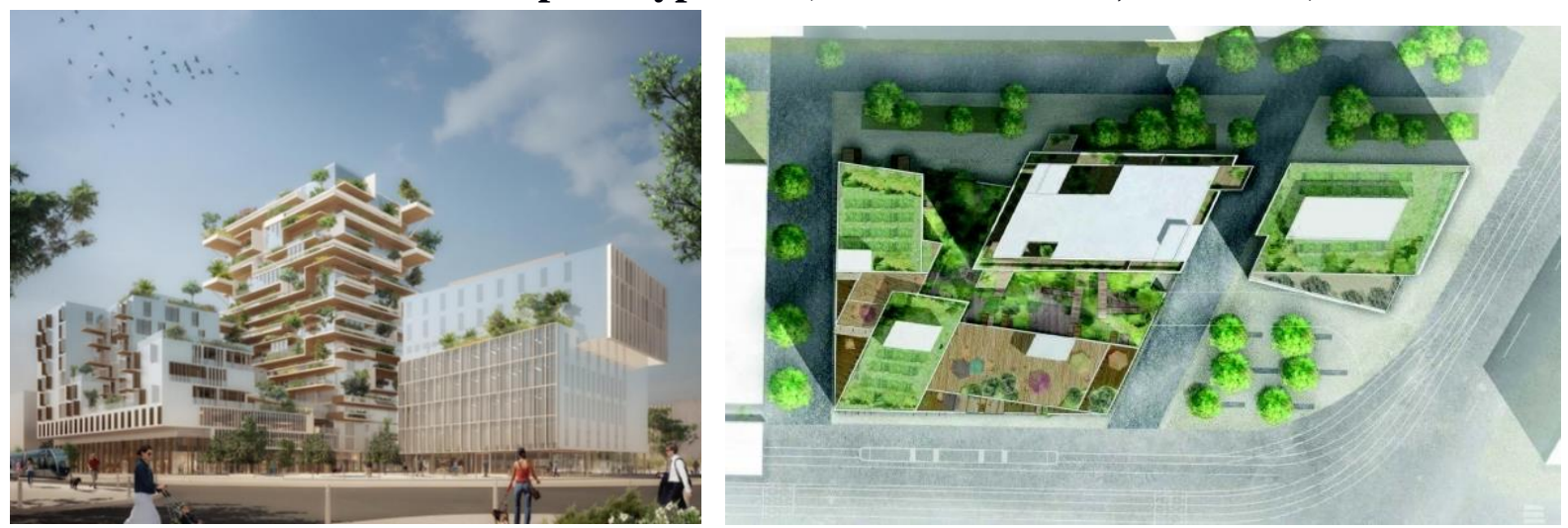

Fig 2. Residential Complex Hypérion.

According to the project, "Hyperion" consists of a 57-meter residential tower, consisting of: a 10-storey residential block and a 7-storey office building. The total area of the complex comprises 160 apartments, $4000 \mathrm{~m}^{2}$ of office space and $500 \mathrm{~m}^{2}$ of stores. In the living tower 82 apartments, five or six on the floor, the most spacious - with an angle two-way orientation, the last level - six duplexes. Unlike today's residential wooden houses (the highest of which is the 49-meter "Treet" in Norwegian Bergen), in the Hyperion, the core of the rigidity, staircase-lift mines and the three lower floors will be carried out in reinforced concrete, and only from the fourth floor-bearing structure will be wooden, 
with columns and beams of laminated wood and lvl-bar and overlays of $200 \mathrm{~mm}$ cross-linked CLT panels. The set of balconies of different geometry determine the discrete, layered image of the building: this form has emerged as a result of light engineering calculations, optimal arrangement of structures to ensure the best insolation of the interior and open public spaces. The plan of the tower in the form of a parallelogram causes the absence of external right angles. Particular importance architects gave to the greenery: public space smoothly flows into the inner garden of the residential part of the complex; In addition, residents have open access to the landscaped terraces on the roof. Architects positioned their project as "an object of landscape design with the buildings included in it.

\section{Residential Complex Messequartier (Location: Graz, Austria)}
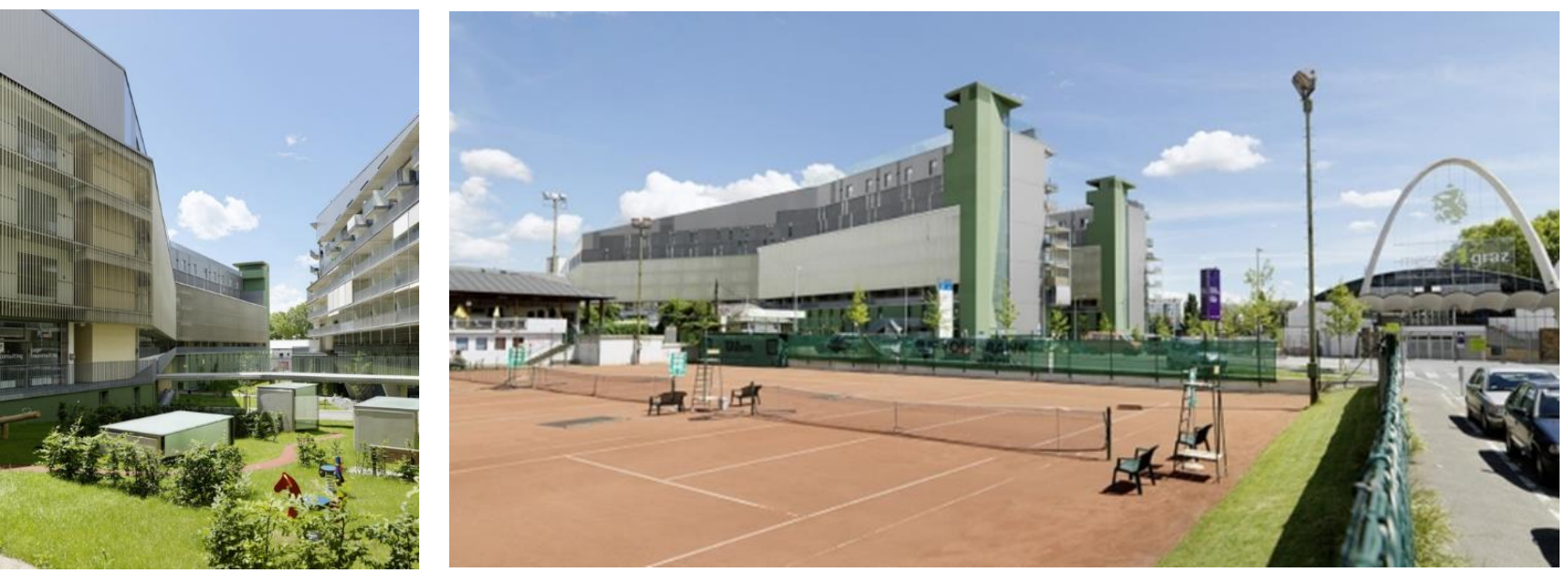

Fig 3. Residential Complex Messequartier.

The complex combines various types of removable dwellings, apartments for sale, student lodging, and apartments for the elderly. There are also office space, kindergarten, and other infrastructure facilities. A meeting of different generations in one home will provide Messequartier with the necessary "social sustainability". In the yard of the complex, there has been created a green public space connected with the adjoining territory through the colonnade, which replaces the part of the first floor: located on the slopes of buildings raised on the supports. The roof terrace includes a swimming pool and a sauna. The complex is equipped with solar collectors, which provide it with $26 \%$ of the required heating and hot water, there is a system for collecting rainwater for irrigation of landscaping. Designed places for bicycles.

\section{Residential Complex Lock House (Location: Amsterdam, Netherlands)}
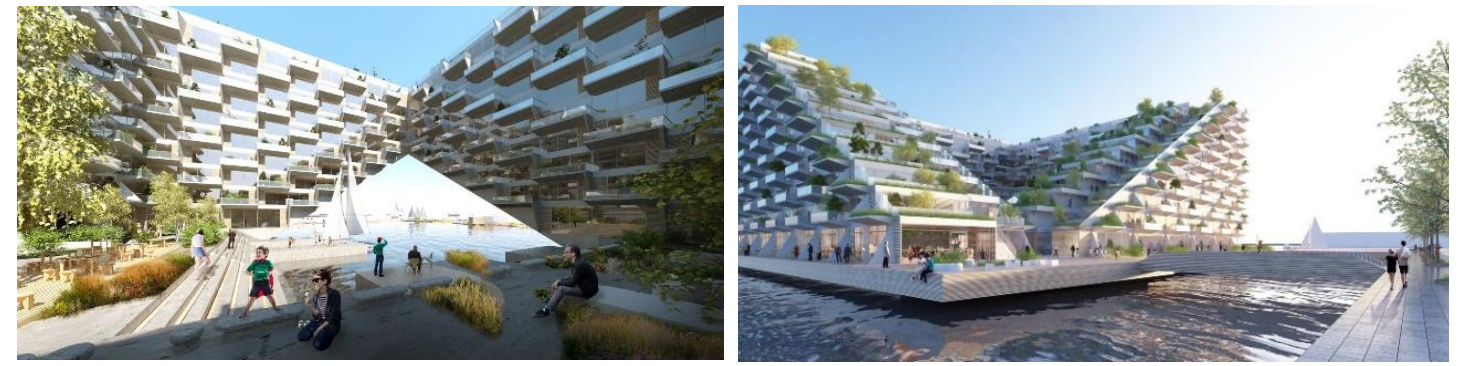

Fig 4. Residential Complex Lock House.

The Lock House complex, designed by BIG International and Barcode Architects, will mark the historic harbor of Amsterdam, which will provide 380 apartments with zero electricity consumption of 4,000 square meters commercial and public spaces, as well as a stop for 30 boats. This is a classic European type of construction with a courtyard, but with a modern refinement. From the courtyard of the complex with landscaped terraces will open the view of the panorama of 
Amsterdam through the massive triangular lumen formed by the design of the building. The many facades of the building will feature a large number of private terraces and a large observation deck at the very top. Lock House is a complex that successfully connects water and the city, designed to reduce overall $\mathrm{CO} 2$ emissions and to encourage the city to use renewable resources to generate electricity in everyday life.

\section{Residential complex with golden balconies Le Toison d'Or from UNStudio, (Location: Belgium, Brussels)}
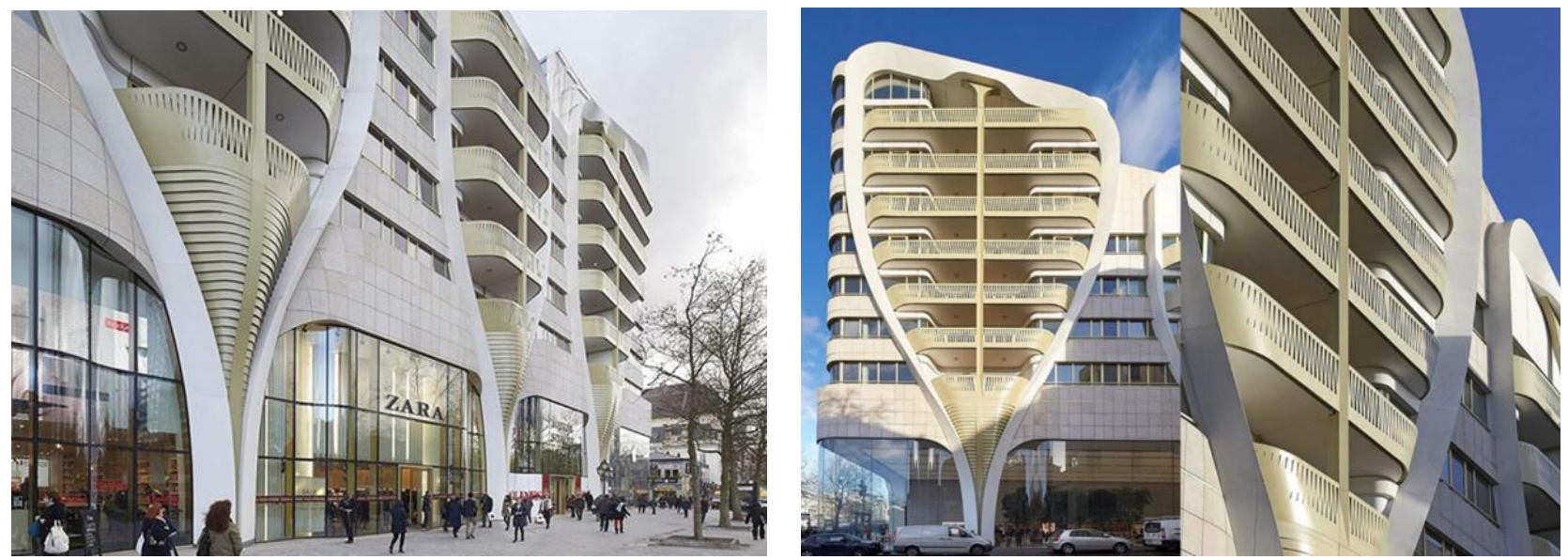

Fig 5. Residential complex with golden balconies Le Toison d'Or from UNStudio.

Dutch Bureau UNStudio, led by Ben van Berkel, built a multifunctional Le Toison d'Or residential complex in the capital of Belgium, which united under one roof commercial areas and elite residential apartments. The house with the golden balconies of Le Toison d'Or in Brussels took almost a quarter. All attention was directed to the outstanding facades of the building. To avoid the monotony inherent in block structures, the facade was decided to break through the alternation of curvilinear vertical frames. The structures are beautifully framed by balconies in the residential part of the complex, leaving open shop windows. Curved shapes are reminiscent of giant leaves of a tree. The author of the project, compared them with balloons, are ready to raise the building in the air. Aluminum golden hue was used to make such impressive balconies. In contrast to the vertical figure of street facades, the rear part of the building is oriented horizontally due to long balconies and elevated to the level of housing in the garden.

Residential complex Le Toison d'Or is constructed taking into account all the standards of stability: qualitative insulation of the facade, including triple glazing, high-level soundproofing, use of glass concrete.

\section{Residential Complex for the Elderly and Youth Future Solund (Location: Denmark, Copenhagen)}
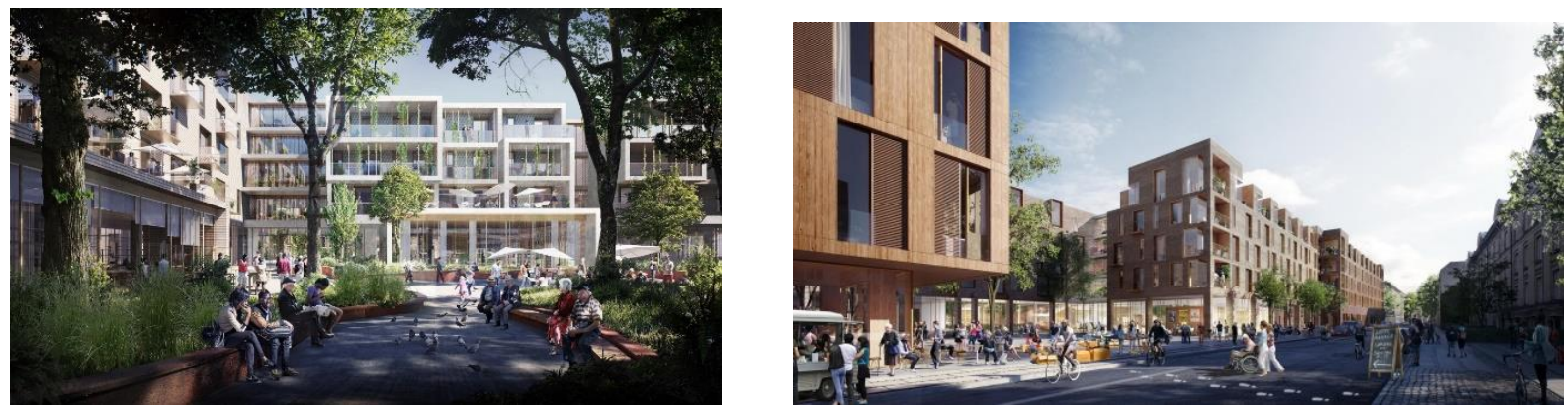

Fig 6. Residential Complex for the Elderly and Youth Future Solund. 
A complex Future Solund typology will be built in Copenhagen, which will combine nursing home, housing for young people and urban public space. Future Solund is an integrated space in the urban environment that provides the opportunity for generations to communicate with each other and enjoy it. According to the project, a building with a total area of 37,895 square meters will accommodate 360 apartments for people in need of special care, 20 apartments for the elderly, 150 for young people (20 of which are intended for autistic people) and many public spaces, from semiprivate to public . According to the authors of the project, such a mixture of functions and typologies will give impetus to the development of the entire city district, will be a place for interaction of the elderly and young, residents, guests and service staff. The central courtyard of the complex - "Square of Generation" - the main space for meetings and communication of residents with each other and guests. The area is "caught" by the internal "street" - a glazed gallery, in which, like the true city streets, there are public "buildings": hairdressers, cafes, studios, game rooms, greenhouses, lecture halls. In the most sunny and quiet south-eastern part of the building is the main block of premises associated with the care of the old. All first-floor apartments have their own open terraces; if the apartments overlook the lake and the park area, the terraces complemented with gardens with a wicket. On the roof overlooking the lake, there is a seating area and an outdoor terrace. The brick facades of the building echoed with buildings around the lake. The residential floors is a corridor type, but this corridor is not quite a corridor, and another "city street", where there are a cafe, winter gardens, and libraries, and in all buildings, there are various facades. The entrance to each the apartment is deepened and forms a niche, which the inhabitants can decorate at their discretion.

The Solund project carries the properties of the urban space into internal planning, adhering to the laws of forming a beautiful city street that maximizes the possible volume of interaction between residents. This attempt to prevent the isolation of a person in the territory, limited by the entrance door of his apartment - the most important for the building.

\section{Market Hall - (Location: Rotterdam, Netherlands)}
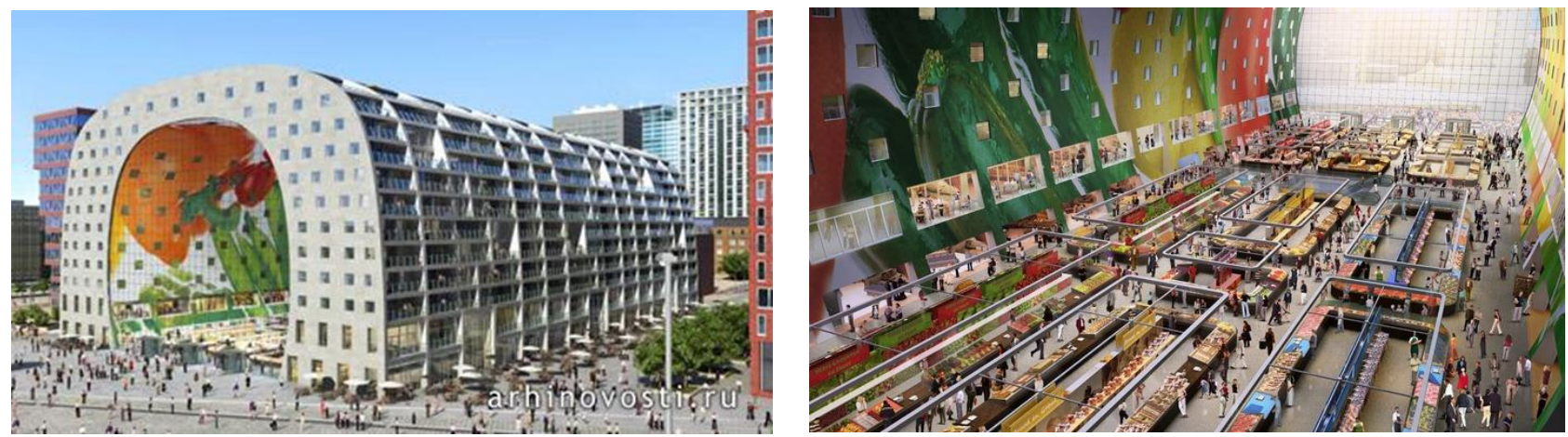

Fig 7. Market Hall.

In the center of Rotterdam, the Dutch architectural studio MVRDV has implemented a project of an unusual hybrid building, which is a combination of a residential building (228 apartments) and an indoor marketplace with 100 retail outlets, shops and restaurants.

The market hall built in the historic place where the city was formed. The project is quite symbolic, but is conceived as a new urban typology; It is a steady combination of products and food, leisure, housing and parking. The 11-story building in shape resembles a gigantic hangar with a total area of 100,000 square meters. Artists Arno Coenen, Iris Roskam, together with a group of designers, vividly painted the walls of the arched vaults, calling their composition "Horn of Abundance". Much of this complex is covered by the market. Under the arched part, there are about 100 food sectors in which only fresh products are sold. And on the premises of the first floor of the house were placed 
shops, restaurants, snack bars, and even a culinary school. An original architectural solution was the construction of a commercial area of apartment apartments: 200 apartments are located on 2 to 10 floors. In addition to retail space and residential premises in the complex at the underground level equipped with a supermarket, a center for logistics for entrepreneurs and parking [9].

\section{Conclusion}

In modern European architecture, the importance of functionality has become increasingly important for the consumer, an architecturally important first and foremost, it is important to have a comfortable and functional environment." The task of the architect is to relieve the notion of an architectural building of the function of commercial representation, to free it from brands and corporate pathos. It satisfies the hybrid housing, which at the beginning of the 21 st century in Europe has the following main tendencies and features:

1. A wide range of apartments for hybrid housing is practiced to meet the needs of different categories of the population.

2. Special attention is paid to the spatial composition of the hybrid building, its thermal and acoustic comfort, and energy-saving technologies.

3. Applying a stepped relief roof, which does not interfere with sunlight to penetrate into the courtyard and flat and forms a terrace. The stepped relief of the roof makes it possible to create a very complex, diverse landscape of the hybrid building. On the one hand, it is quite organic for the metropolis, and on the other hand, it is divided into small, more or less interdependent human modules.

4. Design of balconies of different geometry that provides the best insolation of the interior and open public spaces.

5. High importance is given to planting a hybrid building: the public space gradually turns into internal gardens of the residential part of the complex; In addition, landscaped terraces on the roofs are created.

6. Planning and designing such a number of floors of a hybrid building, which is no different from the silhouette of surrounding historical buildings.

7. Application of the principle of "double facade": internal with continuous glazing with sound insulation, and external - from perforated aluminum shifting panels, which regulates the level of openness of the interior environment.

\section{References}

[1] J. Fenton. "Hybrid Buildings" in Pamphlet Architecture. No. 11: Hybrid Buildings, Princeton Architectural Press, New York, 1985 - 48 p.

[2] M. Musiatowitcz. Hybrid vigor and the art of mixing, Hybrids I: High-Rise

Mixed-Use Buildings, $\mathrm{a}+\mathrm{t}$ architecture publishers, $2008-178 \mathrm{p}$.

[3] Manfred Wolff-Plottegg HYBRID ARCHITEKTUR \& HYPER FUNKTIONEN, Erschienen 2007, Aufl. 1. ISBN, 240 Seiten.

[4] J, Mozas. This is a hybrid, Hybrids II : Low-Rise Mixed-Use Buildings, A+T Architecture Publishers, 2008 . 